\title{
Diversity of ethnomedicinal plants in Churdhar Wildlife Sanctuary of district Sirmour of Himachal Pradesh, India
}

\author{
Radha $^{1^{*}}$, Sunil Puri ${ }^{1}$, Kamna Chandel ${ }^{1}$, Ashok Pundir ${ }^{2 *}$, Mohindra Singh Thakur ${ }^{2}$, Bhawna Chauhan ${ }^{3}$, Kajal Simer ${ }^{3}$, \\ Nidhi Dhiman', Shivani ${ }^{3}$, Yaswant Singh Thakur ${ }^{4}$, Sanjeev Kumar \\ ${ }^{1}$ School of Biological and Environmental Sciences, Shoolini University of Biotechnology and Management Sciences, Solan, India. \\ ${ }^{2}$ School of Mechanical and Civil Engineering, Shoolini University of Biotechnology and Management Sciences, Solan, India. \\ ${ }^{3}$ School of Applied Sciences and Biotechnology, Shoolini University of Biotechnology and Management Sciences, Solan, India. \\ ${ }^{4}$ School of Agriculture, Shoolini University of Biotechnology and Management Sciences, Solan, India. \\ ${ }^{5}$ College of Horticulture and Forestry, Neri, Hamirpur (HP), India.
}

\begin{tabular}{l}
\hline ARTICLE INFO \\
\hline Received on: 14/03/2019 \\
Accepted on: 22/08/2019 \\
Available online: 04/11/2019 \\
\hline Key words: \\
Churdhar, Himachal Pradesh, \\
medicinal plants, Sanctuary, \\
shepherds.
\end{tabular}

\section{ARTICLE INFO}

Accepted on: 22/08/2019

shepherds.

\begin{abstract}
Himachal Pradesh has a great altitudinal range (300-7,000 masl), with varied species, habitats, communities, populations, and ecosystems. There are more than 3,400 different species of plants are reported to be found in Himachal Pradesh. In the state, excess of thousand plant species identified as aromatic and medicinal appear in temperate forests, Shiwalik hills, alpine and sub-alpine pastures. Majority of the inhabitants in Himachal Pradesh belong to different communities and cultures, with specific traditional knowledge. In the remote areas, especially high-altitude regions are contemporary medical amenities, and therefore tribal and rural society mainly depends on native medicinal plants. Herein, we compiled 41 medicinal plant species belonging to same or different families used by migratory shepherds in Churdhar Wildlife Sanctuary of district Sirmour in Himachal Pradesh. This survey will help the medicos, pharmaceutical industry for refining the public healthiness amenities, and maintenance of wild medicinal plant prosperity of the studied zone.
\end{abstract}

\section{INTRODUCTION}

The western Himalaya is a rich collection house of innumerable natural assets, of which vegetation aspect is preeminent. Indian Himalayan region extending from in the NorthWest (Jammu and Kashmir) to the east (Arunachal Pradesh) cover around 4,19,873 $\mathrm{km}^{2}$ area. Indian ethno-medicinal information is a cache, shows a substantial part in rural inhabitants life. Traditional ethnomedicines used by our descendants for their health care and pass orally from one generation to other generation. According to the World Health Organization report, tribal and rural people use

\section{${ }^{*}$ Corresponding Authors}

Radha, School of Biological and Environmental Sciences, Shoolini University of Biotechnology and Management Sciences, Solan, India. E-mail: radhuchauhan7002@gmail.com

Ashok Pundir, School of Mechanical \& Civil Engineering, Shoolini

University of Biotechnology and Management Sciences, Solan, India.

E-mail:ashok.pundir78791@gmail.com ethnomedicines in the treatment of several illnesses. In the year of 2008, worldwide market of ethnomedicines was assessed 83 billion $\$$ and $25 \%$ of new medicines are obtained from the plant species (Jayati et al., 2016; Rana et al., 2015; Rawat and Kharwal, 2011).

Himachal Pradesh has different atmospheric conditions due to changing altitude ranging from 500 to $7,000 \mathrm{~m}$ from north to south and from east to west. Wide differences in altitude, topography, and climate conditions make Himachal Pradesh a suitable habitat for different variety of flora and fauna (Chauhan, 1999; Sood et al., 2001). In general, 200 aromatic plants and 600 medicinal plants are existing here (Sheldon, 1998). The ethnomedicinal plants are significant in natural wares to accomplish all the human needs, such as food, shelter, fiber, and medicine etc. The partnership of plants and human beings is ancient and the antiquity of usage of plants can be assessed through ethnobotanical studies (Samant et al., 2007). There are several methods of ethnobotanical research and those relevant to medicinal plants are archeological search in literature, herbaria, and the field studies. Therefore, the present study was designed to gather information on medicinal use of plants from 
tribal migratory shepherds in Churdhar Wildlife Sanctuary before it was vanished. The present study concentrated on the migratory shepherds as their travelling routine means that they are diligently linked with nature and reliant on natural means for their living, including the treatment of various diseases.

\section{MATERIALS AND METHODS}

\section{Study area}

The Churdhar Wildlife Sanctuary is the important dwindling area of the Himalayan region is situated in the TransGiri hill ranges of Sirmour district, Himachal Pradesh (Fig. 1). The Churdhar Wildlife Sanctuary contains an estimated region of $66.70 \mathrm{~km}^{2}$ with wide altitudinal arrays from 1,900 to $3,647 \mathrm{~m}$ and lies in $77^{\circ} 23^{\prime} 32^{\prime \prime}-77^{\circ} 29^{\prime} 49^{\prime \prime} \mathrm{E}$ and $30^{\circ} 48^{\prime} 37^{\prime \prime}-30054^{\prime} 39^{\prime \prime} \mathrm{N}$ (Anonymous, 2005-2006; Subramani, 2014).

\section{Survey and data collection}

Based on the climatic conditions and altitude aspect, the Churdhar Wildlife Sanctuary harbor's a wide array of enumerated with Botanical name, family, Hindi name, flowering and fruiting, parts used, habit, ailments/diseases treated, and ethnobotanical uses.

The elder migratory shepherds are far aware about the ethnomedicinal information on wild plant species practice than the younger generation. The voucher specimens thus composed, desiccated, and mounted on herbarium sheet, identified by using local Floras (Chowdhery and Wadhwa 1984; Kaur and Sharma, 2004). The species identified by comparing with the authentic specimens present in DD Herbarium of Forest Research Institute Dehradun (Uttarakhand) and Herbarium of Botanical Survey of India, Dehradun (Uttarakhand), vouchers samples for each species are also deposited in the Herbarium of Shoolini University, Solan.

\section{RESULTS AND DISCUSSION}

In present study, total 41 medicinal plants reside to same or different families (Herb 24, Shrub 8, Trees 7, and Climbers 2) were reported in Churdhar Wildlife Sanctuary of district Sirmour in the Western Himalayas (Fig. 2, Table 1). These medicinal plants were commonly used by migratory shepherds in the Churdhar

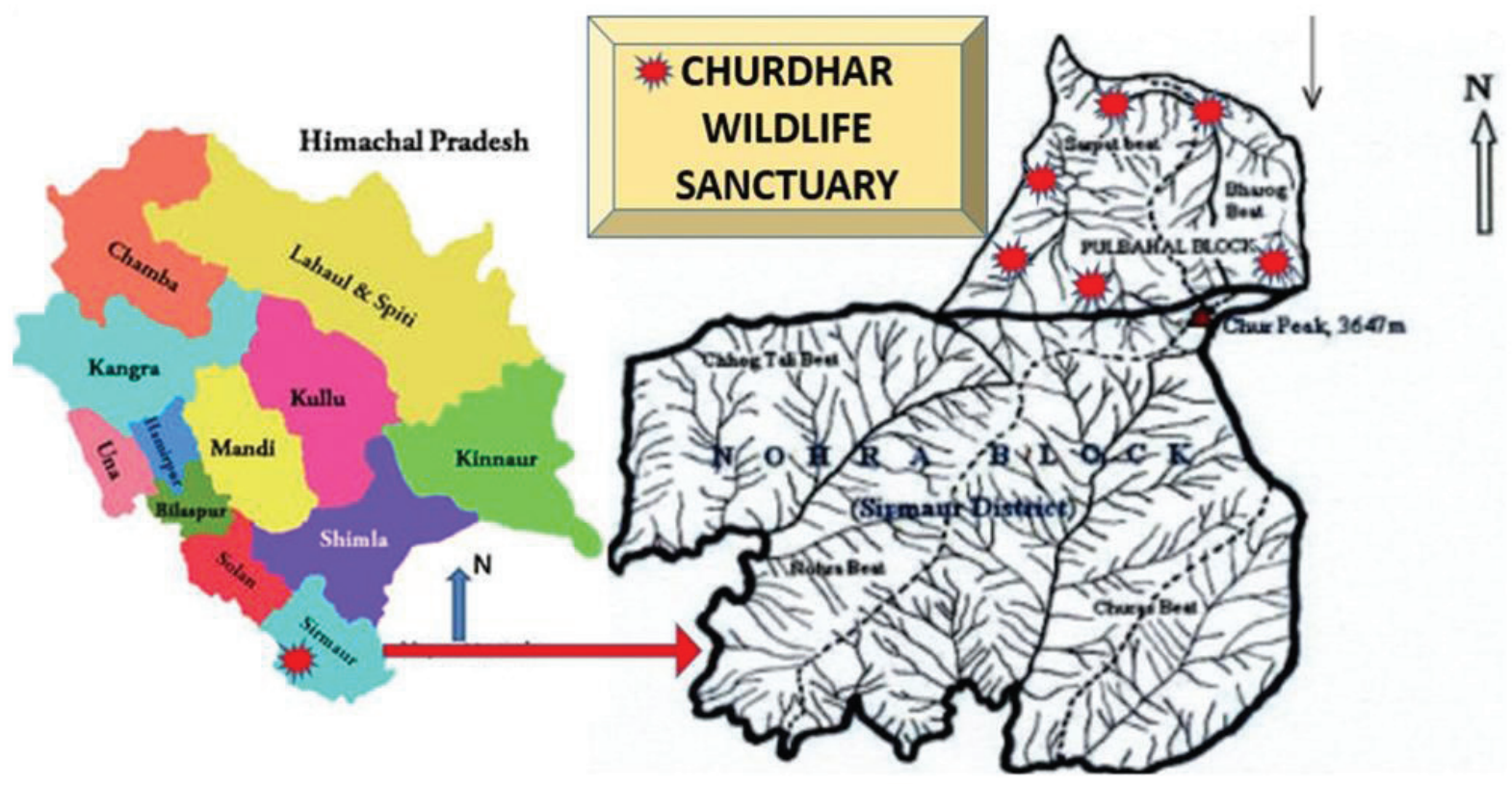

Figure 1. Map of study are.

medicinal plants. Because of its rich medicinal prosperity, the area is remarkable and is relatively vital for thorough studies. The present study documents the use of ethnomedicinal plants by tribal migratory shepherds in Churdhar Wildlife Sanctuary. Regular exploration trips were made to Churdhar Wildlife Sanctuary to explore ethnomedicinal plant species used by shepherds for curing ailments. The shepherd's groups were randomly selected for the interview. The information on ethnomedicinal plants was poised by using a pretested questionnaire, participating remark, and through conversation method in 2017 to 2018. The ethnomedicinal uses of plant assets were well read with both the focused on learning how shepherds were gathering plant material. The plant species that are known are highly regarded in ethnomedicinal practices are

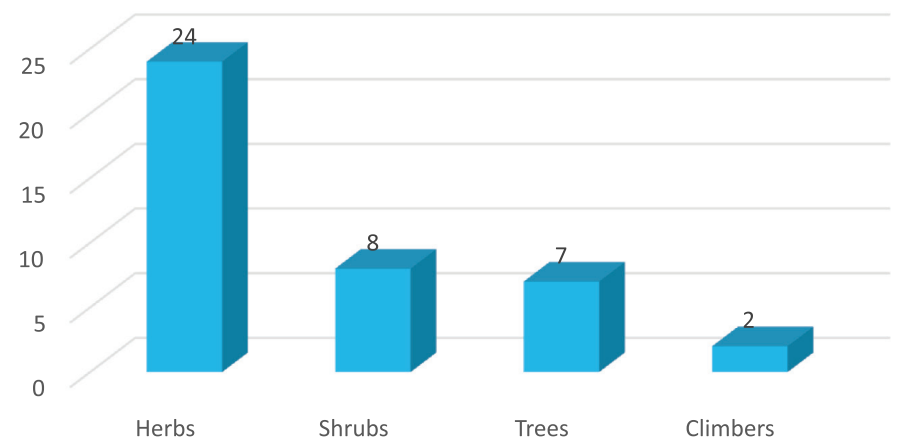

Figure 2. Ethnomedicinal plants used by shepherds in Churdhar Wildlife Sanctuary. 


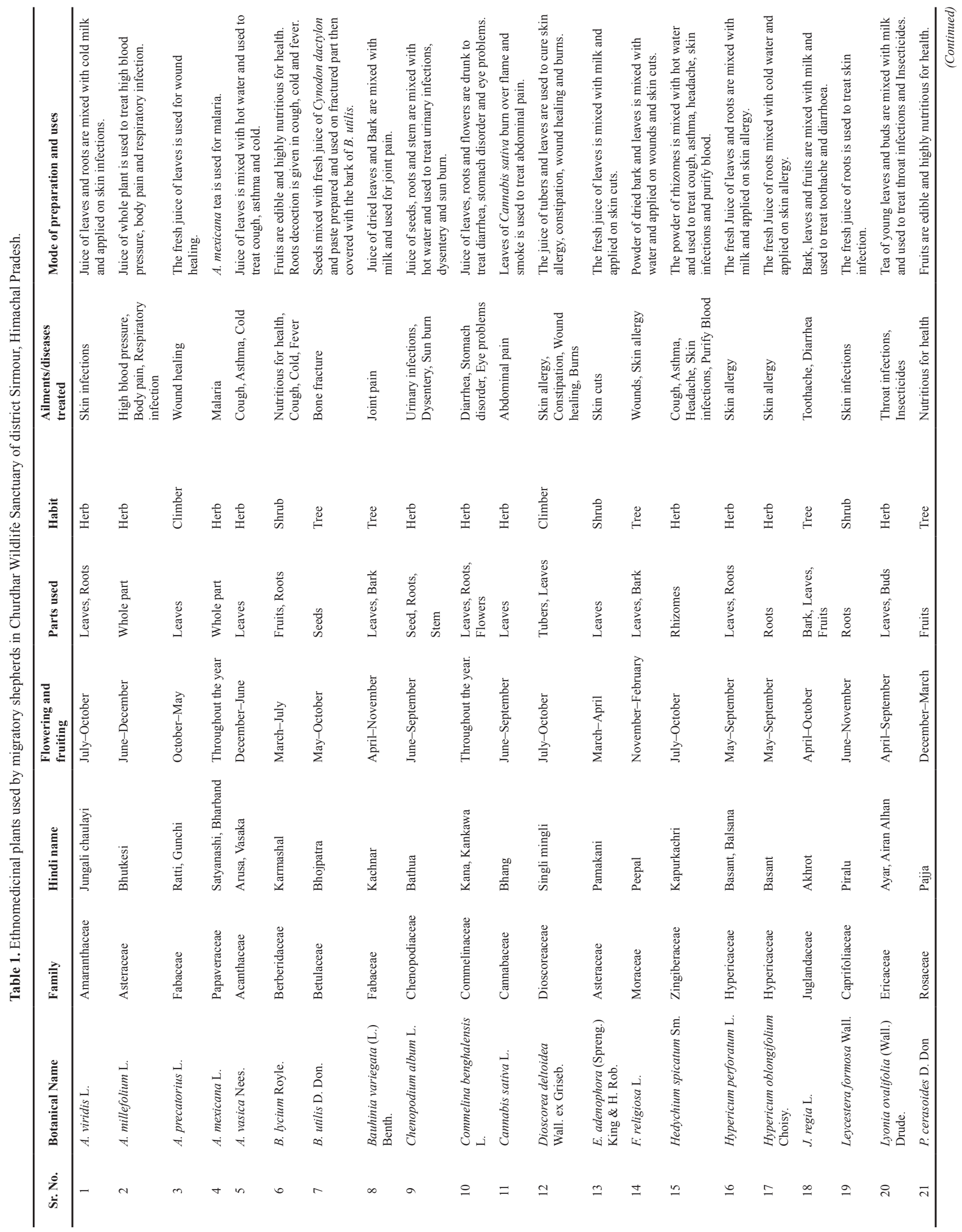




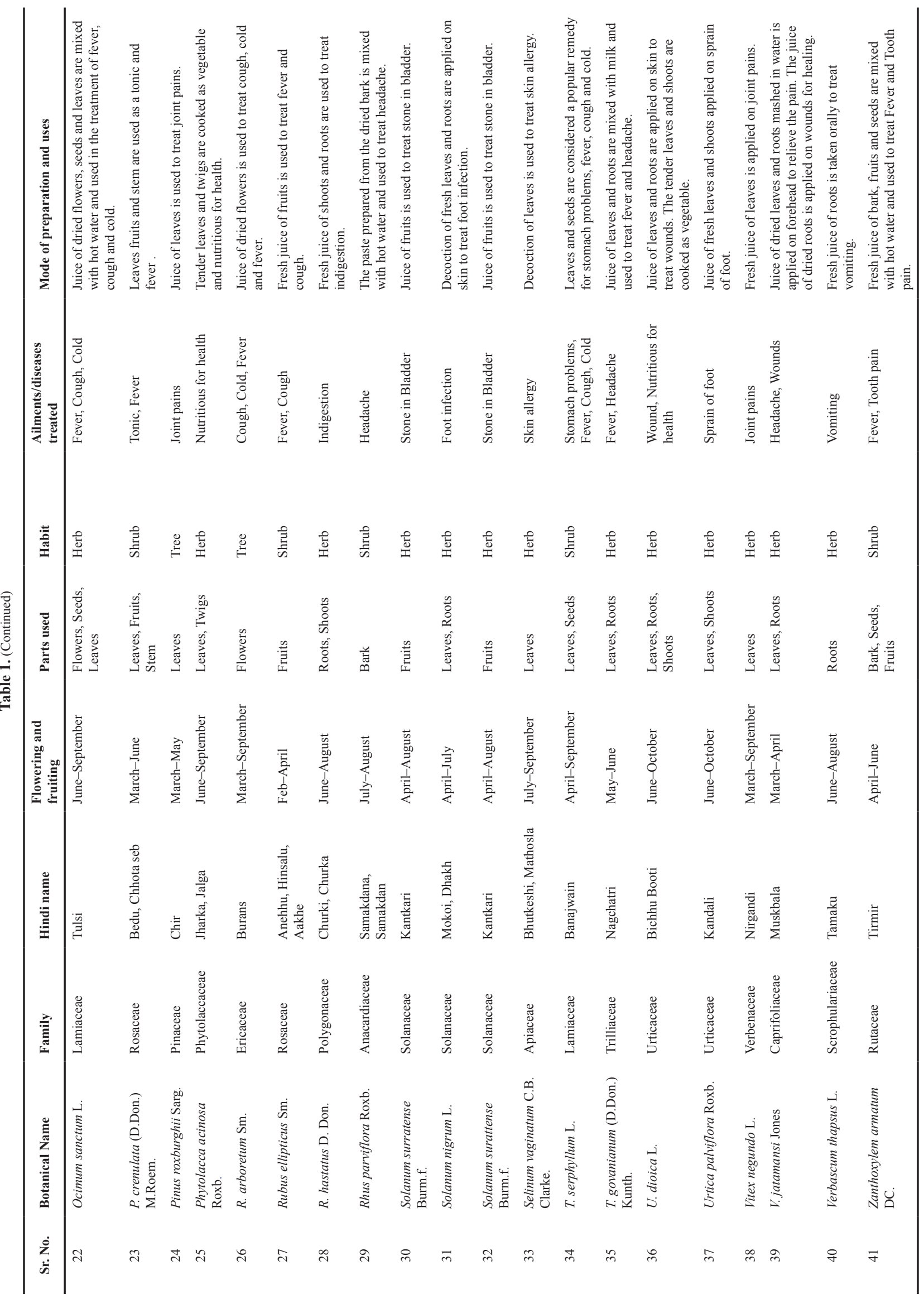


Sanctuary. The maximum plant species were used for urinary infections, dysentery, sunburn, cough, cold, skin disease, diarrhea, joint pain, stomach infection, for wound healing, etc. Some plants species in extension to their medicinal prominence have religious and cultural significance, such as Betula utilis, Ficus religiosa, and Cannabis sativa. Migratory shepherds passage in between the bends of Himalayan elevations ranges from high hills of more than $4,000 \mathrm{msl}$ to low hills or plains of $350 \mathrm{msl}$. Some ethnomedicinal plants used by tribal peoples are earlier reported by many researchers from different parts of Himachal Pradesh named as Amaranthus viridis, Achillea millefolium, Abrus precatorius, Argemone mexicana, Adhatoda vasica, Berberis lycium, B. utilis, Dioscorea deltidea, Eupatorium adenophora, Juglans regia, Prunus cerasoides, Pyracantha crenulata, Rhododenfron arboretum, Rumex hastatus, Thymus serphyllum, Trillium govanianum, Urtica dioica, Valeriana jatamansi, etc. (Chauhan, 1999; Radha, 2018; Radha et al., 2018). The seasonal movement of shepherds is precise significant for the existence of the livestock in the tough environmental circumstances, including high temperature in the summertime at low elevations and analyzed and cold temperature in winter season at high hills. The seasonal movement of shepherds makes propensity on the natural resources including the innate medicinal plant species for a healthcare structure. The migratory shepherds also hoard and gather some medicinal plant parts in their homes and offsite passage camp site for imminent uses.

In present study shepherds interestingly, informed that their preference for ethnomedicinal plants are A. mexicana, A. vasica, B. utilis, D. deltidea, R. hastatus, B. lycium, J. regia, $V$. jatamansi, T. serphyllum, T. govanianum, and $U$. dioica. The plant species such as T. govanianum, V.jatamansi, and T. serphyllum. are become rare and very difficult to get from our surroundings that due to over exploitation of medicinal plants from studied areas.

Hence, there is an immediate requisite to preserve ethnomedicinal knowledge through documented literature and proper communication with younger generation. Because the medicinal plants of Himalayan region have been reducing due to absence of proper documentation and knowledge in present generation. Therefore, scientific attention on pharmacology and chemistry is required on traditional used wild medicinal plants before its extinction from human civilization.

\section{CONCLUSION}

Himachal Pradesh is a source of medicinal plants and ethnomedicinal information associated with these plants. Application of plant assets has age-old practice of the shepherds residing hilly state of Himachal Pradesh. In present study, it is concluded that medicinal plants play significant role to treat several diseases of shepherds named as high blood pressure, body pain, respiratory infection, skin infections, malaria, cough, cold, asthma, cuts, wound healing, urinary infections, dysentery, sunburn, joint pain, etc. The present study advises to familiarize some management procedures to be taken jointly with the tribal shepherd's societies in order to preserve medicinal plant resources from becoming vanished. In addition to the above-mentioned species, the migratory shepherds also use many other plants. These plant species form an integral form of their way of life, and hence always been valued.

Finally, the present study also endorses scientific rationality and toxicity tests of the described medicinal plants used for the treatment of various different human diseases. The information gathered from the study concerning the medicinal plant species used by the shepherds requires a through phytochemical analysis, including alkaloid separation and is promotion along with some clinical trials. This could help in making mass alertness concerning their preservation, promotion of ethno-medicinalbotany information with in the area also paying to the conservation and improvement of the gene bank of such economically important plant species before they are last permanently.

\section{ACKNOWLEDGMENT}

The authors would like to thank the tribal migratory shepherds for their inclination to shave their valuable experiences and knowledge on wild medicinal plants. The authors also would like to thank the Forest Research Institute, Dehradun (Uttarakhand) and Botanical Survey of India, Dehradun (Uttarakhand) for specimen identification.

\section{FINANCIAL SUPPORT}

None.

\section{CONFLICTS OF INTEREST}

The authors declare that there are no conflicts of interest.

\section{REFERENCES}

Anonymous. Revised working plan for the forests of Rajgarh Forest Division, Himachal Pradesh, vol. 1, 387 pp, 2005-2006.

Chauhan NS. Medicinal and aromatic plants of Himachal Pradesh, Indus Publ. Co., New Delhi, India, p 500, 1999.

Chauhan NS, Khosla PK. Commercially important medicinal plants of Himachal Pradesh In: Khosla PK (ed.). Tends in Tree Sciences ISTS Publications, India, pp 81-9, 1988.

Chowdhery HJ, Wadhwa BM. Flora of Himachal Pradesh, Analysis, vols. 1-3. Botanical Survey of India, Calcutta, 860 pp, 1984.

Jayati R, Rajedo K, Ashish C, Archana S, Ruchi B. A survey to explore the herbal wealth and its utility as edibles, ethnomedicine and ethnoveterinary practices in Nanda Devi Biosphere Reserves (NDBR), Uttarakhand as a step to Bio Prospection. Pharm Anal Acta, 2016; 7:514.

Kaur H, Sharma M. Flora of Sirmaur (Himachal Pradesh). Bishen Singh Mahendra Pal Singh, Dehra Dun, 770 pp, 2004.

Rana M, Kabra A, Kabra R, Rana M, Dhatwalia V. Plant species used by localsa s Ethano-Medicine in Gohar Tehsil Distt. Mandi Region of North Western Himalaya. Pharma Tutor, 2015; 3(4):47-52.

Rawat DS, Kharwal AD. Traditional Health Practices by 'Kinners'-A Tribe in Alpine and SubAlpine Himalayas of kinnaur (Himachal Pradesh), India. J Life Sci Leafl, 2011; 22:1048-55.

Radha, Puri S. Study of Ethnomedicinal Plants used by Migratory Shepherds in Renuka Forest Division of District Sirmour (H.P.) Western Himalaya. Bio Bull, 2018; 4(2):103-9.

Radha, Puri S, Kumar S. Diversity and use of wild edible plants by migratory shepherds in the Himachal Pradesh of the Western Himalayas, India. J Med Plants Res, 2018; 12(30):601-10.

Sheldon JM, Balick M, Laird S. Is using medicinal plants compatible with conservation? Plant Talk April, 1998; 29-31. 
Subramani SP, Kapoor KS, Goraya GS. Additions to the floral wealth of Sirmaur District, Himachal Pradesh from Churdhar Wildlife Sanctuary. JThreatened Taxa, 2014; 6(11):6427-52; doi:10.11609/JoTT. o2845.6427-52

Samant SS, Pant S, Singh M, Lal M, Singh A, Sharma A, Bhandari S. Medicinal Plants in Himachal Pradesh, north western Himalaya, India. Int J Biodiver Sci Manag, 2007; 234-51.

Sood SK, Nath R, Kalia DC. Ethnobotany of Cold Desert Tribes of Lahaul-Spiti (N.W. Himalaya). Deep Public., New Delhi, 2001.
How to cite this article:

Radha, Puri S, Chandel K, Pundir A, Thakur MS, Chauhan B, Simer K, Dhiman N, Shivani, Thakur YS, Kumar S. Diversity of ethnomedicinal plants in Churdhar Wildlife Sanctuary of district Sirmour of Himachal Pradesh, India. J Appl Pharm Sci, 2019; 9(11):048-053. 